\title{
Calcitonin inhibits invasion of breast cancer cells: Involvement of urokinase-type plasminogen activator (uPA) and uPA receptor
}

\author{
BO HAN ${ }^{1,2}$, MISA NAKAMURA ${ }^{1}$, GENGYIN ZHOU ${ }^{2}$, AIKO ISHII $^{1}$, ATSUSHI NAKAMURA $^{1}$, \\ YANHUA BAI $^{1,2}$, ICHIRO MORI $^{1}$ and KENNICHI KAKUDO ${ }^{1}$ \\ ${ }^{1}$ Department of Pathology, Wakayama Medical University, Kimiidera 811-1, Wakayama 641-8509, Japan; \\ ${ }^{2}$ Department of Pathology, Shandong University, Wenhua West Road 44, Jinan 250012, P.R. China
}

Received October 24, 2005; Accepted December 14, 2005

\begin{abstract}
There is a growing body of evidence indicating that calcitonin (CT) and calcitonin receptor (CTR) are involved in the regulation of cell growth, differentiation, and survival and in tissue development. However, the precise functional role of CT/CTR in breast cancer is still unknown. It is well established that the urokinase plasminogen activator (uPA) system plays an important role in breast cancer invasion and metastasis. The goal of this study was to investigate the effects of CT on regulation of the UPA system and invasive capacity of breast cancer cells. In the highly invasive MDA-MB-231 cell line, $10^{-8} \mathrm{M}$ CT decreased both uPA and UPAR mRNA and protein expression which was associated with inhibition of the extracellular signal-regulated kinase (ERK) 1/2 pathway. Furthermore, two weeks of CT administration to nude mice inhibited the expression of uPA mRNA in primary tumors by $25 \%(\mathrm{P}<0.05)$, as compared to control, untreated animals. CT also inhibited the invasiveness of MDA-MB-231 cells by $37 \%$ $\left(10^{-8} \mathrm{M} \mathrm{CT}, \mathrm{P}<0.05\right)$, as determined by a Matrigel invasion assay. To the best of our knowledge, this is the first report describing a direct effect of CT on breast cancer cell invasion. Our data might suggest a close link between CT signaling, the UPA-mediated pathway, and breast cancer invasion.
\end{abstract}

\section{Introduction}

Calcitonin (CT) is a 32 amino-acid polypeptide hormone of thyroidal origin, whose main physiological role is to inhibit osteoclastic bone resorption (1). There is a growing body of evidence that $\mathrm{CT}$ and its receptor (CTR) are involved in the regulation of cell growth, differentiation, and survival and

Correspondence to: Dr Misa Nakamura, Department of Pathology, Wakayama Medical University, Kimiidera 811-1, Wakayama 641-8509, Japan

E-mail: marumisa@wakayama-med.ac.jp

Key words: calcitonin, urokinase plasminogen activator, uPAR, invasion, breast cancer in tissue development (2-4). It has been demonstrated that cell proliferation is inhibited when human breast cancer cells T47D are treated with CT (5). There is also evidence that CT is involved in cell survival and apoptosis $(6,7)$. However, a direct effect of CT on breast cancer invasion has not been reported.

Tumor invasion and metastasis are the leading causes of morbidity and mortality in patients with breast cancer $(8,9)$. These events involve multiple processes requiring, as an intermediate step, destruction of the extracellular matrix (ECM) and basement membrane. One of the major proteolytic systems involved in this step is the urokinase-plasminogen activator (uPA) system, comprising uPA, its cell surface receptor $\mathrm{UPAR}$, and its inhibitors plasminogen activator inhibitor types 1 and 2 (PAI-1 and PAI-2, respectively) (10-13). Upon binding to its receptor, uPA induces direct plasminmediated proteolysis or indirect activation of other proteinases, such as metalloproteases (MMPs) $(10,13)$. In addition, uPA is associated with cell proliferation, chemotaxis and angiogenesis (10). PAI-1 inactivates uPA, but it also has an important role in cell adhesion and cell migration $(10,12)$. The four major components of this system have been established as prognostic factors in primary breast cancer by various research groups (10-13). In particular, uPA and PAI-1 reached level-I evidence in terms of their prognostic impact $(14,15)$, according to proposed guidelines (16). As a result of these compelling clinical data, the uPA system represents one of the most of interesting targets for breast cancer therapy. To date, experimental in vitro and in vivo studies have shown that inhibition of uPA activity or uPA-binding to UPAR inhibits tumor growth and reduces or abolishes metastasis (17-19).

In several human cancers, mitogenesis and expression of UPA and UPAR are frequently activated through common signaling complexes and pathways (20). Most mitogens and several oncogenes transmit signals through the proto-oncogene ras, which initiates a phosphorylation cascade resulting in the activation of a pair of $M r 42,000$ and 44,000 mitogen-activated protein kinases, also known as extracellular signal-regulated kinase (ERK) 1/2 (21). It is well documented that the binding of CT to CTR leads to the activation of multiple signaling pathways, including the ERK 1/2 pathway (2). We have reported that CT suppressed constitutive phosphorylation of ERK 1/2 in DU145 prostate cancer cells (21). Our ongoing research has also shown that CT suppresses phosphorylation of ERK1/2 
in MDA-MB-231 breast cancer cells (unpublished data). In this regard, Ma et al have shown that UPA-uPAR system acts within a positive feedback loop with phosphorylated ERK $1 / 2$ in MDA-MB-231 cells, which may promote cellular proliferation and cell invasion (22). Disruption of this loop, for example, via treatment with PD098059, a MEK-1 inhibitor, was reported to inhibit cell growth and invasiveness $(22,23)$. Therefore, we hypothesized that CT might be also a potential modulator of the uPA system in MDA-MB-231 cells.

In the present study, the effects of CT on regulation of the uPA system and invasive capacity of MDA-MB-231 cells were investigated. We show that i) CT treatment causes down-regulation of UPA and UPAR in MDA-MB-231 cells, with the ERK1/2 pathway being involved in mediating this effect; ii) CT inhibits the invasiveness of MDA-MB-231 cells in vitro; and iii) $\mathrm{CT}$ treatment results in a decrease in $\mathrm{UPA}$ mRNA expression within MDA-MB-231-derived xenografts in vivo.

\section{Materials and methods}

Reagents and antibodies. Salmon CT was purchased from Peninsula Laboratories, Inc. (Belmont, CA). Anti-human uPAR 3937 monoclonal antibody (MoAb) was obtained from American Diagnostics (Greenwich, CT). PD98059, a MEK1 inhibitor, was obtained from Calbiochem (La Jolla, CA).

Cell culture. Human breast cancer cell lines MDA-MB-231, MDA-MB-435, T47D and MCF-7 were purchased from the American Type Culture Collection (Manassas, VA) and maintained in Dulbecco's modified Eagle's medium (DMEM) (Gibco BRL, Invitrogen) with 10\% FBS (HyClone, Logan, UT). LCC6 cells were a gift from Dr M.E. Lippman (Georgetown University, Washington, DC) and maintained in modified improved MEM (Gibco BRL, Invitrogen) containing 5\% FBS. All cells were cultured in a humidified atmosphere containing $5 \% \mathrm{CO}_{2}$ at $37^{\circ} \mathrm{C}$.

Cell growth experiments. DNA synthesis was assessed in MDA-MB-231, T47D and MCF-7 cells by measuring [ $\left.{ }^{3} \mathrm{H}\right]-$ thymidine incorporation. Briefly, cells were seeded at a density of $1 \times 10^{6}$ cells/well in 8 -well plates. After being cultured in $0.5 \%$ serum-containing DMEM for $18 \mathrm{~h}$, cells were treated with different concentrations of $\mathrm{CT}$, which was immediately followed by supplement of $1.0 \mu \mathrm{Ci} / \mathrm{ml}\left[{ }^{3} \mathrm{H}\right]$-thymidine. After incubation for $12 \mathrm{~h}$ at $37^{\circ} \mathrm{C}$, the media were aspirated, and cells were washed twice with ice-cold PBS, and then incubated with ice-cold 5\% trichloroacetic acid (TCA) for $15 \mathrm{~min}$. After aspiration of the TCA, the cells were dissolved in lysis buffer containing $0.4 \mathrm{~N} \mathrm{NaOH}$, and an aliquot was analyzed by liquid scintillation counting (LS6500, Beckman Coulter, Inc., Fullerton, CA). Eight replicate wells were prepared for each CT concentration. The results were expressed as the mean of determinations from three independent experiments.

$R N A$ isolation and reverse transcription-PCR analysis. Total cellular RNA was extracted using the Ultraspec RNA Isolation system (Biotecx Labs. Inc., Houston, TX). Total RNA ( $2 \mu \mathrm{g})$ was transcribed to cDNA via use of the SuperScript RT-PCR kit (Life Technologies, Inc., Gaithersburg, MD). cDNAs of human uPA, uPAR, PAI-1 and CTR mRNA transcripts were amplified using the following primers: uPA forward 5'AAGGACTACAGCGCTGACAC-3'; reverse 5'-AACTCCT GCAGGCTTCAGTC-3'. uPAR forward 5'-CGGTGCATGC AGTGTAAGAC-3'; reverse 5'-AGCAGGAGACATCAATG TGG-3'. PAI-1 forward 5'-TCATGGACAGACCCTTCCTC-3'; reverse 5'-GGACATTCACTCTGCCACCT-3'. CTR forward 5'-GACAAAGAGATCTTCAAAAATC-3'; reverse 5'-TTCT GATGGATCAAAATCCGG-3'.

PCR amplification was accomplished with an initial denaturation step at $95^{\circ} \mathrm{C}$ for $5 \mathrm{~min}$, followed by 35 cycles of denaturation at $94^{\circ} \mathrm{C}$ for $30 \mathrm{sec}$, annealing at either $62^{\circ} \mathrm{C}$ (for UPA, uPAR and PAI-1) or $58^{\circ} \mathrm{C}$ (for CTR) for $30 \mathrm{sec}$, and extension at $72^{\circ} \mathrm{C}$ for $30 \mathrm{sec}$. RT-PCR analysis with $B$-actin primers (forward 5'-AAGAGAGGCATCCTCACCCT-3' and reverse 5'-TACATGGCTGGGGTGTTGAA-3') was used as an internal RNA control. PCR conditions for $\beta$-actin were the same as that used for analysis of the CTR gene. PCR products were analyzed by electrophoresis on a $2 \%$ agarose gel containing ethidium bromide.

Northern blot analysis. The cDNA probes synthesized via RT-PCR were a 789-bp fragment covering nucleotides 863-1652 of the $u P A$ mRNA transcript (GeneBank accession no. NM_002658) and a 792-bp fragment covering nucleotides 496-1288 of the $u P A R$ mRNA transcript (GeneBank accession no. NM_002659). Northern blot analysis was performed as described previously (24). Briefly, total RNA was extracted using the Ultraspec RNA Isolation System. Total RNA $(20 \mu \mathrm{g})$ was electrophoresed on $1.2 \%$ agaroseformaldehyde gels, transferred to nylon membrane and fixed by Gs gene linker (Bio-Rad, Lab., Hercules, CA). Hybridization was performed using probes labeled with $\left[\alpha^{-32} \mathrm{P}\right]-\mathrm{ATP}$ via the Hotprime DNA labeling kit (GeneHunter, Nashville, TN). Quantitative analysis of the autoradiographs was performed using the NIH Image densitometry program, with the levels of 18s rRNA (as determined by staining with ethidium bromide) being used for normalization purposes. The data were expressed as the mean of determinations from two independent experiments.

Western blot analysis. Western blotting was performed as previously described (21). Briefly, 70-80\% confluent cells were cultured in $0.5 \%$ serum-containing medium for $18 \mathrm{~h}$, and then treated with $10^{-8} \mathrm{M} \mathrm{CT}$. At indicated time-points, cells were washed with ice-cold PBS once and extracted in ice-cold lysis buffer (21). Protein $(20 \mu \mathrm{g})$ was directly electrophoresed on a $12 \%$ SDS-PAGE gel and then transferred to Immobilon-P polyvinylidene difluoride membrane (Millipore, Bedford, MA). The membrane was incubated with anti-uPAR MoAb (clone 3937, 1:1,000) overnight at $4^{\circ} \mathrm{C}$. The secondary antibody was horseradish peroxidase (HRP)-coupled antimouse IgG (Dako, Glostrup, Denmark) (1:1500), and the signals were detected with an enhanced chemiluminescence (ECL) kit (Amersham, Buckinghamshire, UK). To check the amounts of proteins transferred to the membrane, $\beta$-actin was used as control, as detected by an anti- $\beta$-actin MoAb (Ab-1, clone JLA20; Oncogene) at a 1:10,000 dilution. Three independent experiments were performed. 
Measurement of UPA and PAI-1 protein in conditioned medium by ELISA. MDA-MB-231 cells were pre-cultured in $0.5 \%$ serum-containing medium for $18 \mathrm{~h}$, plated at $5 \times 10^{4}$ cells in $60-\mathrm{mm}$ dishes, and treated with or without $10^{-8} \mathrm{M} \mathrm{CT}$. After incubation for different time-periods, the medium was removed into tubes and centrifuged at 3,000 rpm for $15 \mathrm{~min}$ at $4^{\circ} \mathrm{C}$. uPA and PAI-1 ELISA kits (Imubind, American Diagnostica, Greenwich, CT) were used to measure the concentration of these proteins in cell culture supernatants. The cells were counted and the data corrected for cell number. The data were expressed as the mean of determinations from two independent experiments.

Matrigel invasion assay. Invasion capacities of MDA-MB-231 cells were analyzed using Biocoat Matrigel invasion chambers (Becton-Dickinson, Bedford, MA). Briefly, cells treated with or without $\mathrm{CT}$ for $24 \mathrm{~h}$ were trypsinized and resuspended in serum-free medium. Cell suspension $(0.5 \mathrm{ml})\left(2.5 \times 10^{4}\right.$ cells $)$ was plated within the upper insert of the chamber in either the presence or absence of CT. The bottom chamber contained $10 \% \mathrm{FBS}$ as a chemoattractant. After incubation for $22 \mathrm{~h}$ at $37^{\circ} \mathrm{C}$, cells that had invaded to the lower surface of the membranes were fixed and stained with Diff-Quick stain kit (International Reagents Co., Kobe, Japan). For quantification, cells were counted in five randomly selected microscopic fields (x200). Three independent experiments were performed.

Animals. Female, athymic BALB/c-nu/nu mice (5-6 weeks of age; CLEA Japan, Inc., Tokyo, Japan), were used for the studies. Animals were maintained in a specific pathogenfree environment under controlled conditions of light and humidity. All protocols for in vivo studies were approved by the Institutional Animal Care and Use Committee of the Wakayama Medical University.

Tumor cell inoculation and CT injection. MDA-MB-231 cells were injected into the subaxillary mammary fat pads of mice at both sites $\left(5 \times 10^{6}\right.$ cells/site $)$. Animals were randomly divided into two groups immediately after tumor cell inoculation. Experimental group received s.c. injection of CT everyday (240 ng/day) in a volume of $70 \mu 1$. CT was dissolved in isotonic saline solution $(0.9 \% \mathrm{NaCl})$ containing $1.2 \mathrm{M}$ aminocaproic acid ( $\mathrm{pH}$ 6.0) as peptidase inhibitor; the control group received comparable injection of isotonic saline solution. All mice were sacrificed 14 days after inoculation and primary tumors from experimental $(n=6)$ and control group $(n=5)$ were excised accordingly, with fresh tissues being stored at $-80^{\circ} \mathrm{C}$ immediately.

Real-time RT-PCR analysis. Total RNA was extracted from the primary tumors of mice to analyze uPA and UPAR mRNA levels in vivo. RNA $(2 \mu \mathrm{g})$ was used to generate first-strand cDNA via reverse transcriptase (Superscript; Gibco, Grand Island, NY). The primer and probe sequences used for detection of GAPDH mRNA levels were as described previously (25). The primers and probes used for analysis of uPA and uPAR transcripts were purchased from Applied Biosystems Japan Ltd. (Applied Biosystems Japan Ltd, Tokyo, Japan). PCR amplification was performed with $5 \%$ of the resultant

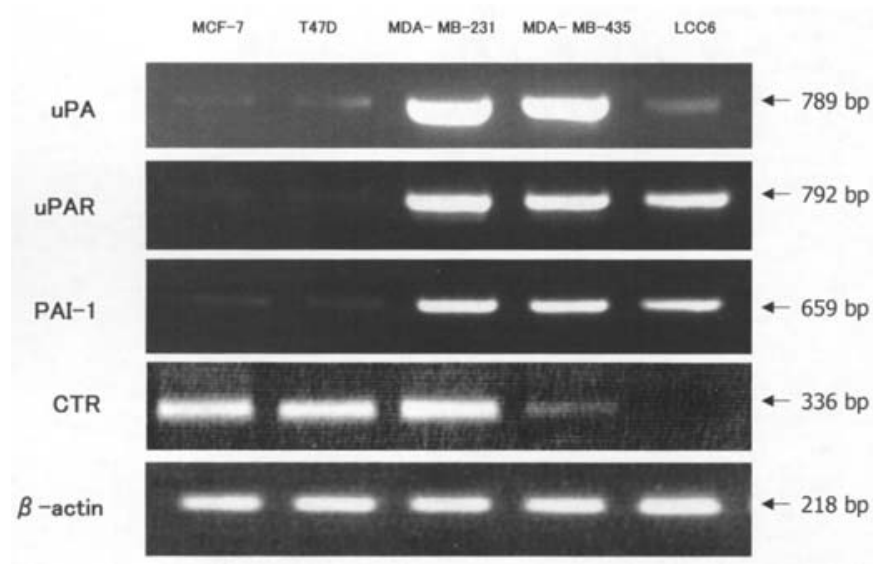

Figure 1. Characterization of human breast cancer cell lines for uPA system and CTR gene expression. Total RNA was extracted from various breast cancer cell lines and analyzed for uPA, uPAR, PAI-1 and CTR gene expression via RT-PCR analysis, as described in Materials and methods. Level of $\beta$-actin was used as an internal control.

cDNA in a final volume of $50 \mu 1$ containing $900 \mathrm{nM}$ of each primer, $250 \mathrm{nM}$ probe, and $0.5 \mathrm{X}$ PCR reagent mix (TaqMan Universal PCR Master Mix; Applied Biosystems). The amplification protocol comprised incubations at $50^{\circ} \mathrm{C}$ for $2 \mathrm{~min}$, and $95^{\circ} \mathrm{C}$ for $10 \mathrm{~min}$, followed by 40 cycles of incubation at $95^{\circ} \mathrm{C}$ for $15 \mathrm{sec}$ and $60^{\circ} \mathrm{C}$ for $1 \mathrm{~min}$. The reactions were run in triplicate, with mean values being determined by comparing threshold cycle $\left(\mathrm{C}_{\mathrm{t}}\right)$ values. The method used to calculate $\mathrm{C}_{\mathrm{t}}$ for statistical testing has been described previously (25).

Statistical analysis. All results were expressed as mean \pm SE and statistical comparisons were based on a One-way ANOVA or Student's t-test using StatView software 5.0 (SAS Institute, Cary, NC, USA). Significance was considered as $\mathrm{P}<0.05$.

\section{Results}

Characterization of human breast cancer cell lines for $u P A$, UPAR, PAI-1 and CTR gene expression. The expression levels of uPA, uPAR, PAI-1 and CTR mRNA in various breast cancer cell lines are shown in Fig. 1. In agreement with studies by Guo et al (26) and Holst-Hansen et al (27), uPA, UPAR, PAI-1 transcripts were found to be barely detectable in MCF-7 and T47D cells, both of which are ER-positive, of low invasive potential, and representative of an early stage in terms of breast cancer progression. In contrast, the ERnegative, highly invasive MDA-MB-231, MDA-MB-435, and LCC6 cells, which are representative of later stages in respect to breast cancer, exhibited high levels of uPA system gene expression. CTR mRNA is expressed in all breast cancer cell lines, apart from LCC6 cells. As MDA-MB-231 cells exhibit the highest level of UPA and UPAR mRNA expression in our series and it is more invasive in vitro than either MDA-MB-435 or LCC6 cells (28), we selected it as a cell model for our study.

Effect of CT on DNA synthesis in MDA-MB-231, MCF-7, and T47D cells. To explore whether CT has direct anti-proliferative 


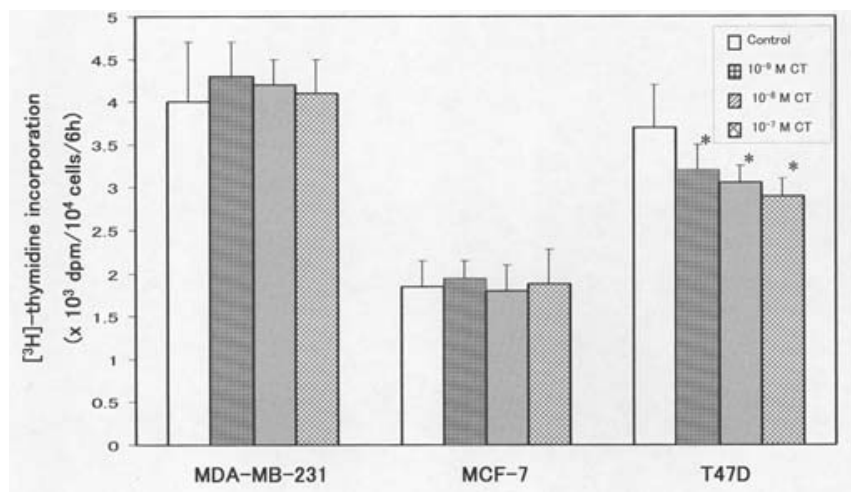

Figure 2. Effect of CT on DNA synthesis in breast cancer cells. Breast cancer cells were cultured with or without $\mathrm{CT}\left(10^{-9}, 10^{-8}, 10^{-7} \mathrm{M}\right)$, which was immediately followed by supplement of $\left[{ }^{3} \mathrm{H}\right]$-thymidine. After incubation for $12 \mathrm{~h}$, incorporated thymidine was measured by liquid scintillation counting, as described in Materials and methods. Columns, mean of eight wells; bars, SE; ${ }^{*} \mathrm{P}<0.05$. Similar results were obtained from three separate experiments. properties or not, we examined its effect on DNA synthesis in breast cancer cells by quantifying $\left[{ }^{3} \mathrm{H}\right]$-thymidine incorporation. As shown in Fig. 2, CT treatment reduced the extent of DNA synthesis in T47D cells in a concentrationdependent fashion. For example, CT treatment at $10^{-7} \mathrm{M}$ decreased $\left[{ }^{3} \mathrm{H}\right]$-thymidine incorporation in T47D cells by $22 \%$ as compared to the control $(\mathrm{P}<0.05)$. However, CT treatment had little effect on DNA synthesis in MDA-MB231 and MCF-7 cells.

$C T$ decreased $m R N A$ expression and secretion of $U P A$ in $M D A-M B-231$ cells. Using Northern blot analysis, we showed that CT treatment at $10^{-8} \mathrm{M}$ suppressed uPA mRNA $(2.4 \mathrm{~kb}$ transcript size) expression in MDA-MB-231 cells, reaching maximal inhibition after $6 \mathrm{~h}$ (4-fold) (Fig. 3A). Accordingly, we measured the effect of CT on the secretion of uPA from MDA-MB-231 cells. Our results showed that $10^{-8} \mathrm{M} \mathrm{CT}$
A
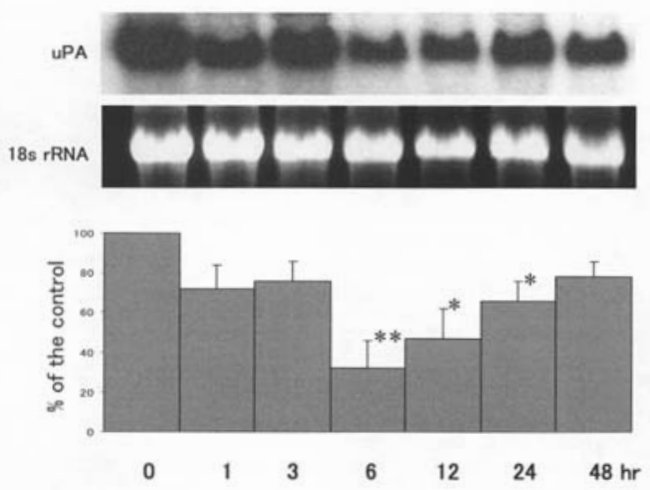

B

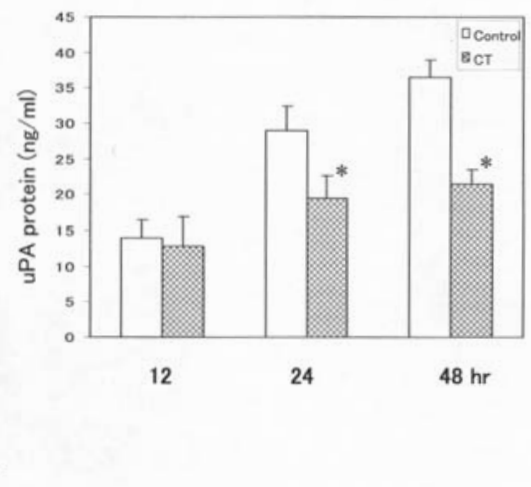

Figure 3. The effect of CT on the mRNA level and secretion of uPA in MDA-MB-231 cells. Cells at $80 \%$ confluence were cultured in $0.5 \%$ serum-containing medium for $18 \mathrm{~h}$, and incubated in the presence or absence of $\mathrm{CT}\left(10^{-8} \mathrm{M}\right)$ for the indicated time. (A), Total RNA was isolated, and levels of uPA mRNA was detected by Northern blot analysis. To control for equal loading of the gels, the expression of uPA was normalized to level of 18s rRNA (as determined from ethidium bromide-stained gel). To compare expression levels among samples, the expression levels of the uPA gene in the control cells were set to $100 \%$. Quantitation of uPA mRNA is shown in the bottom panel. (B), Conditioned media were assayed for uPA protein level using an ELISA kit. Data are presented as the mean of results from two experiments, each performed in triplicate. Bars $\pm \mathrm{SE} ;{ }^{*} \mathrm{P}<0.05 ;{ }^{* *} \mathrm{P}<0.01$.
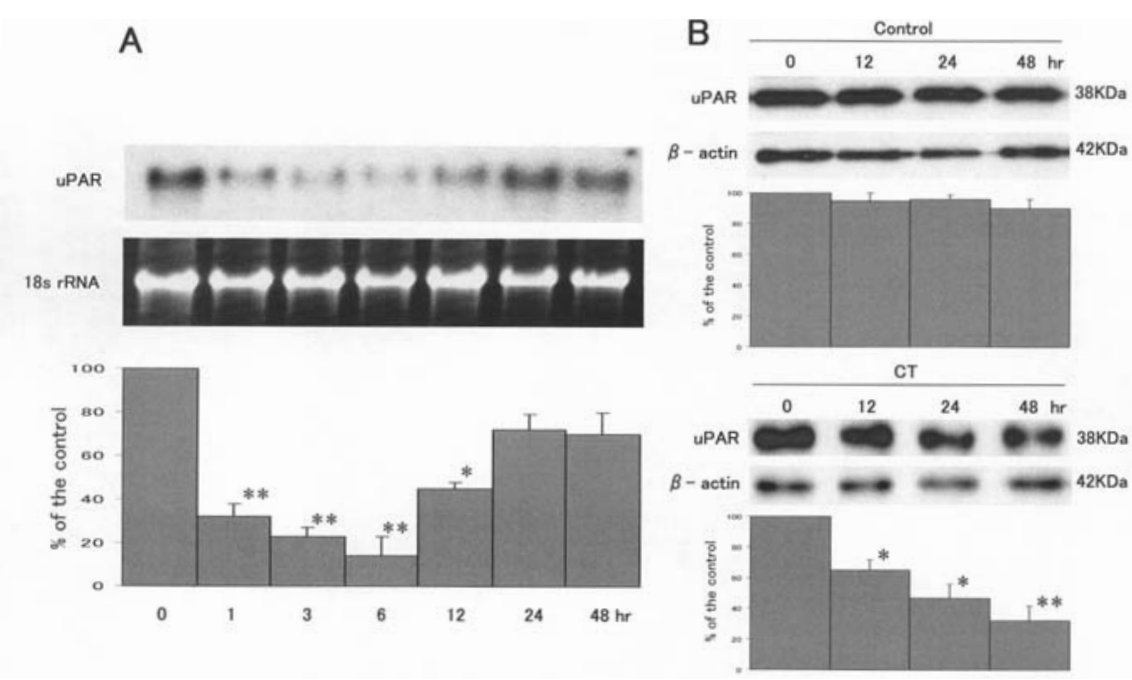

Figure 4. The effect of CT on the expression of uPAR mRNA and protein in MDA-MB-231 cells. Cells were cultured in $0.5 \%$ serum-containing medium for $18 \mathrm{~h}$ before treatment with or without $\mathrm{CT}\left(10^{-8} \mathrm{M}\right)$ for indicated periods of time. (A), uPAR mRNA expression levels as detected by Northern blot analysis. The expression of uPAR was normalized to the level of 18s rRNA, with the expression level of uPAR mRNA in the control cells being set to $100 \%$. Quantitation of uPAR mRNA is shown in the bottom panel. (B), Total cell lysates were prepared and subjected to Western blot analysis for assessment of uPAR protein expression. The same blots were stripped and reprobed with an anti- $\beta$-actin antibody. Data are presented as the mean of results from two experiments for Northern blot analysis and three experiments for Western blot analysis. Bars $\pm \mathrm{SE} ;{ }^{*} \mathrm{P}<0.05 ;{ }^{* *} \mathrm{P}<0.01$. 
A
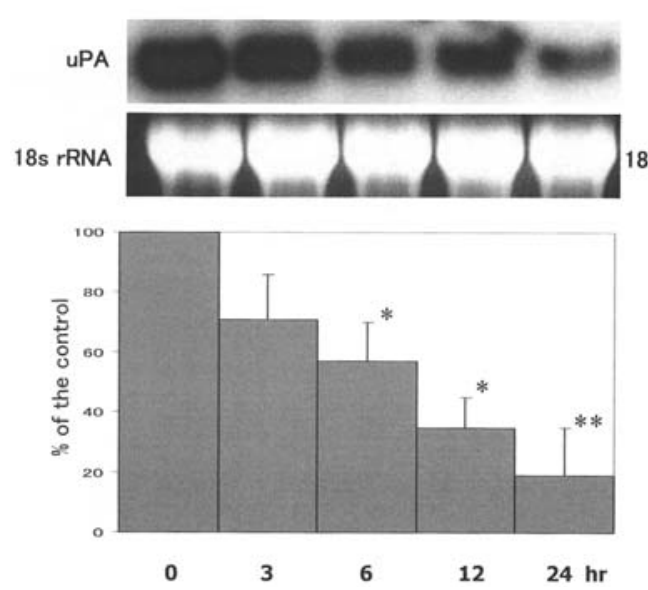

B
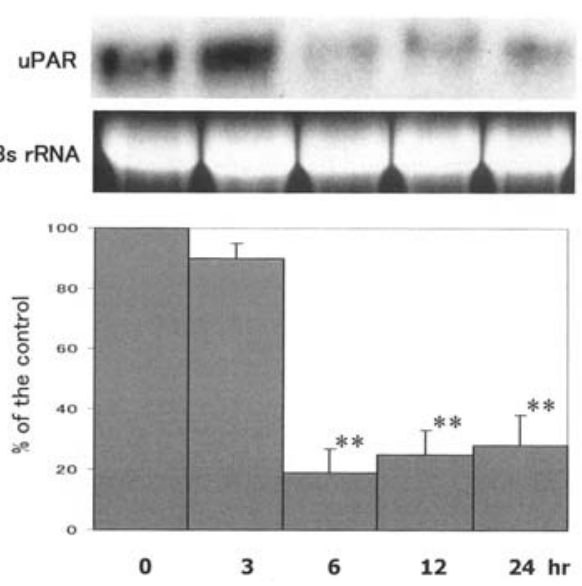

Figure 5. PD98509 blocks uPA and uPAR mRNA expression in MDA-MB-231 cells. Cells were treated with PD98059 (50 $\mu$ M) or with vehicle alone for indicated time in $0.5 \%$ serum-containing medium. Total RNA isolates were analyzed for uPA (A) and uPAR (B) mRNA expression by Northern blot analysis. The level of $18 \mathrm{~s}$ rRNA in each sample was used for normalization. Quantitation of uPA and uPAR mRNA is shown in the bottom panel. Bars \pm SE; * $<0.05$; ${ }^{* *} \mathrm{P}<0.01$

significantly inhibited the secretion of uPA (by $31 \%$ after treatment for $24 \mathrm{~h}$ and by $41 \%$ after $48 \mathrm{~h}$ ), as compared with that exhibited by untreated cells $(\mathrm{P}<0.05)$ (Fig. 3B).

Suppression by CT of UPAR $m R N A$ and protein expression in $M D A-M B-231$ cells. We next evaluated the potential regulation of uPAR mRNA expression by $\mathrm{CT}$ in MDAMB-231 cells. CT rapidly inhibited the expression of uPAR mRNA (by 3-fold after $1 \mathrm{~h}$ ), with this inhibitory effect lasting $12 \mathrm{~h}$ (Fig. 4A). To determine whether the observed changes in the level of uPAR mRNA expression were associated with a corresponding decrease in the expression of uPAR protein, Western blot analysis was performed. From this, the expression of the uPAR protein in MDA-MB-231 cells was observed to be significantly decreased after 24 and $48 \mathrm{~h}$ of CT treatment, as compared with those in control groups $(\mathrm{P}<0.05)$ (Fig. 4B).

Suppression of UPA and UPAR expressions by CT is associated with inhibition of ERK1/2 pathway. Ongoing research in our laboratory has demonstrated that CT inhibited phosphorylation of ERK1/2 in MDA-MB-231 cells (unpublished data). To confirm that the ERK1/2 pathway in response to CT is critical for its effect on the regulation of UPA and UPAR in MDA-MB231 cells, we treated the cells with PD98095, a specific MEK1/2 inhibitor. Consistent with the findings of Ma et al (22), decreased UPA and UPAR mRNA expression was observed by Northern blot analysis (Fig. 5). Thus, it seems very likely, that CT inhibits uPA and UPAR expression via regulation of the ERK1/2 pathway.

$C T$ inhibited invasion of MDA-MB-231 cells. The ability of CT to mediate down-regulation of uPA and uPAR expression led us to explore the effect of CT on the invasive capacity of MDA-MB-231 cells. Cells were pre-treated with CT for $24 \mathrm{~h}$, followed by transfer to invasion chambers. The doses of CT used were selected on the basis of our previous reports and those used in other investigations $(21,24,29)$. As shown in Fig. 6, CT suppressed invasiveness of MDA-MB-231 cells in

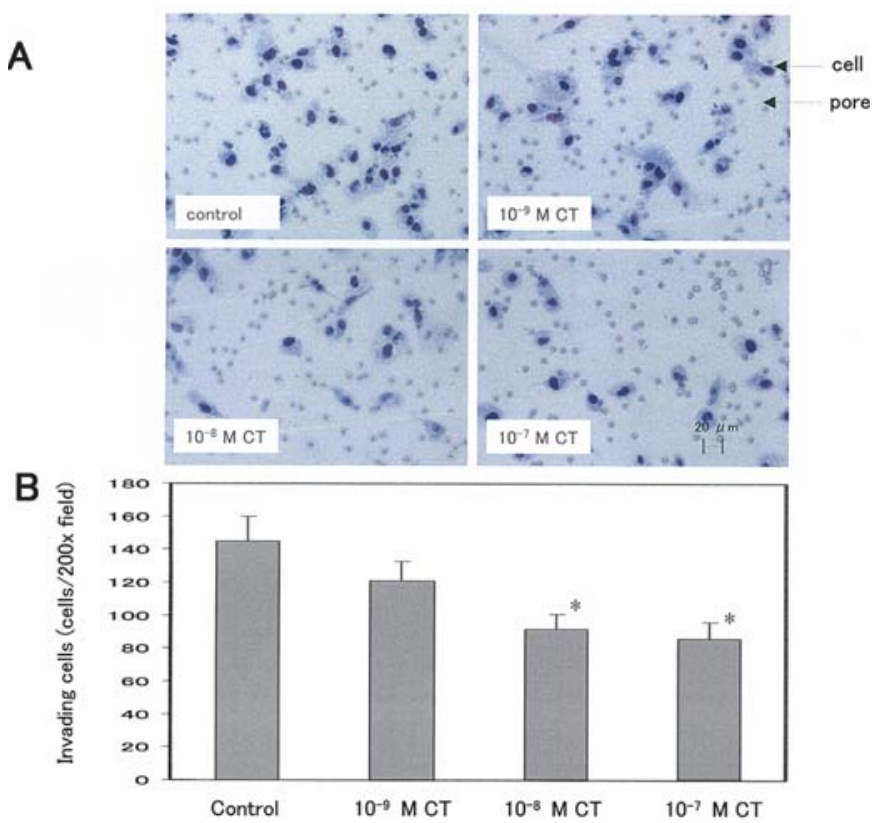

Figure 6. Inhibition of invasion by CT in MDA-MB-231 cells. MDA-MB-231 cells were pretreated for $24 \mathrm{~h}$ with CT $\left(10^{-9}, 10^{-8}, 10-^{7} \mathrm{M}\right)$, and cell invasion was determined after an additional $22 \mathrm{~h}$ of incubation with CT. Shown above (A) is a section of the visual field of one representative experiment (magnification $\times 200$ ). The data shown are the means \pm SE of duplicate determinations. Similar results were obtained in two additional experiments. Bars $\pm \mathrm{SE} ;{ }^{*} \mathrm{P}<0.05$; scale bar, $20 \mu \mathrm{m}$.

a dose-dependent manner. CT treatment at $10^{-7} \mathrm{M}$ and $10^{-8} \mathrm{M}$ inhibited cell invasion by 41 and $37 \%$, respectively, when compared to control cells $(\mathrm{P}<0.05, \mathrm{n}=3)$. We next evaluated if pretreatment of the cells was necessary for this anti-invasive effect. For this purpose, untreated cells were added to invasion chambers in the presence of increasing concentrations of CT, but no significant inhibitory effect was found (data not shown). These results suggest that CT may slowly induce these changes in the phenotype of MDA-MB-231 cells, which counteract the ability of these cells to invade. 
A

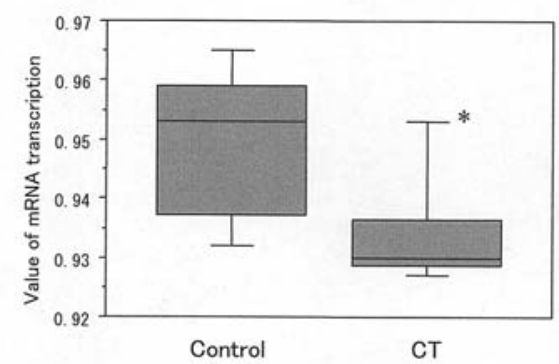

B

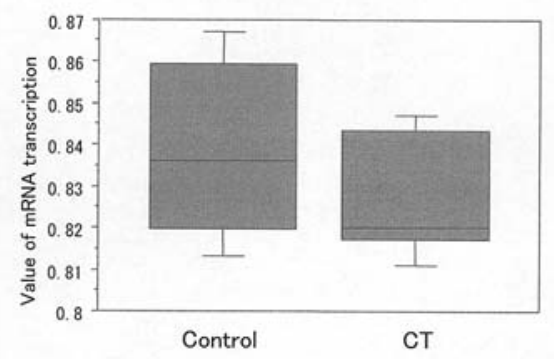

Figure 7. Real-time RT-PCR analysis of uPA and uPAR mRNA levels in vivo. Values of uPA (A) and uPAR (B) mRNA transcriptions were determined from real-time RT-PCR analysis, as described in Materials and methods. Data were expressed a percentage of the mean control value \pm SE; ${ }^{*} \mathrm{P}<0.05$ (Student's t-test, two-tailed).

CT decreased UPA $m R N A$ levels in vivo. Using relative quantitation by real-time RT-PCR analysis, uPA mRNA levels from tumors of mice receiving $\mathrm{CT}$ treatment were shown to be decreased by $25 \%(\mathrm{P}<0.05)$, as compared with those of the control group. Alteration of uPAR mRNA levels showed the same tendency, but this did not reach statistical significance (Fig. 7).

\section{Discussion}

Breast cancer is a hormone-dependent malignancy that generally initiates as a less aggressive, hormone therapyresponsive type and gradually progresses to a highly invasive and hormone therapy-resistant phenotype (11). Finding an appropriate strategy for treating the latter stage of this disease is a challenging problem in the clinical setting. Receptor-bound uPA is now believed to play an important role in several cancers, with it being associated with late stage cancers (10). From the series of breast cancer cell lines analyzed in our study, MDA-MB-231 cells are hormone-insensitive, highly invasive and representative of late stage breast cancer. Animals inoculated with MDA-MB-231 develop large tumors that can metastasize in vivo (18). In this cell line, high levels of uPA and UPAR expression correlate with invasive capacity and provide a link between uPA expression and tumor stage (26).

Recently, much interest has arisen in terms of the relationship between the CT/CTR system and breast cancer. Firstly, $\mathrm{CT}$ is able to inhibit growth of the breast cancer cell line T47D, as well as abolish the growth stimulation provided by either epidermal growth factor or insulin in this cell model $(5,30)$. Secondly, CT is suggested to be involved in the regulation of metastasis-related genes in breast cancer, such as tissue inhibitors of metalloproteases (TIMP) and parathyroid hormone-related protein (PTHrP), a potential local mediator of skeletal metastasis $(29,31)$. Thirdly, we and other investigators have shown that CTRs are commonly expressed in breast cancer cell lines and primary breast cancers $(32,33)$. Using a laser capture microdissection technique, we also reported that decreased CTR mRNA expression was much more frequently seen in cases with lymph node metastasis and lymphatic invasion (33). However, a precise functional role for CT/CTR in breast cancer is still largely unknown.
We have previously reported that $\mathrm{CT}$ induced significant up-regulation of UPA in the LLC-PK1 cell line (24). In the present study, for the first time, we could show that CT was also a potent regulator of the uPA system in the metastatic human breast cancer cell line MDA-MB-231. CT treatment down-regulated both uPA and UPAR mRNA and protein expression, leading to a decrease in UPA secretion. The inhibitory effect of CT treatment on uPA mRNA expression was further verified in vivo. CT treatment did not exhibit any significant effect on PAI-1 expression in MDA-MB-231 cells (data not shown). We highlighted these findings because potent paracrine UPA-uPAR signaling may be required for breast cancer metastasis (10). It is recognized that the UPA-uPAR system acts within a positive feedback loop with phosphorylated ERK 1/2 in MDA-MB-231 cells. The MEK inhibitor PD98059, which targets a kinase upstream of ERK1/2, has been shown to substantially decrease UPA and UPAR mRNA expression (22); this finding was confirmed in our present study. Strategies that block this loop, in some conditions, may have therapeutic efficacy. On the other hand, CT has been used for treatment of osteoporosis (3). Therefore, our new data provides additional information to revive a long forgotten area of CT and cancer biology.

Another important finding in this study is that $\mathrm{CT}$ inhibits the invasiveness of MDA-MB-231 cells. To the best of our knowledge, this is the first report describing a direct effect of $\mathrm{CT}$ on breast cancer cell invasion. This observation is of great interest, since invasiveness of tumor cells represents one of several important factors necessary for metastasis. Our result has clearly shown that $\mathrm{CT}$ inhibits tumor cell invasion in a concentration-dependent manner. However, this effect was only seen in cells which had been cultured in the presence of $\mathrm{CT}$ for a prolonged period of $24 \mathrm{~h}$. Assuming that inhibition of invasion requires changes in gene transcription and protein modulation, this observation is not surprising. In MDA-MB-231 cells, Holst-Hansen et al (27) and Guo et al (26) have suggested that in vitro invasiveness is dependent on uPA activity. The MMP system is another family of invasion-associated proteases in breast cancer (34); however, CT had no apparent effect on MMP-9 expression in this cell line (data not shown). Therefore, it is most likely that CT-mediated inhibition of 
MDA-MB-231 cell invasion in vitro depends on the downregulation of $\mathrm{uPA}$ and $\mathrm{UPAR}$.

Our present data support the hypothesis that CT, under certain conditions, may protect against breast cancer invasion, which would help to explain why decreased CTR mRNA expression has been much more frequently seen in cases with advanced breast cancer. However, in contrast to our findings, Sabbisetti et al (35) and Chigurupati et al (36) have shown that CT increased the invasiveness of prostate cancer cells, as well as stimulating intratumoral angiogenesis by directly acting on endothelial cells. In our opinion, these conflicting data might be partially explained by the fact that CTRs exist in several isoforms in different tissues and are functionally heterogeneous (2). The CT-activated signaling pathway is not only tissue- and cell type-specific, but sometimes even cell cycle-specific (37).

In conclusion, our findings that $\mathrm{CT}$ regulates the level of expression of uPA and uPAR and the invasion of breast cancer cells opens a new avenue for investigations examining more closely the link between CT-signaling, the urokinase pathway, and breast cancer invasion. We propose that the MDA-MB-231 cell line is a useful model of advanced breast cancer and can be used to develop novel therapeutic agents involving the CT/CTR system.

\section{Acknowledgements}

This work was supported in part by Grants-in-Aid (15591353) for Scientific Research (C) and Grants-in-Aid (16659095) for Exploratory Research from the Ministry of Education, Science, Sports and Culture of Japan.

\section{References}

1. Chambers TJ and Magnus CJ: Calcitonin alters behaviour of isolated osteoclasts. J Pathol 136: 27-39, 1982.

2. Pondel M: Calcitonin and calcitonin receptors: bone and beyond. Int J Exp Pathol 81: 405-422, 2000.

3. Zaidi M, Inzerillo AM, Moonga BS, Bevis PJ and Huang CL: Forty years of calcitonin - where are we now? A tribute to the work of Iain Macintyre, FRS. Bone 30: 655-663, 2002.

4. Ismail PM, DeMayo FJ, Amato P and Lydon JP: Progesterone induction of calcitonin expression in the murine mammary gland. J Endocrinol 80: 287-295, 2004.

5. Ng KW, Livesey SA, Larkins RG and Martin TJ: Calcitonin effects on growth and on selective activation of type II isoenzyme of cyclic adenosine $3^{\prime}: 5^{\prime}$-monophosphate-dependent protein kinase in T 47D human breast cancer cells. Cancer Res 43: 794-800, 1983 .

6. Plotkin LI, Weinstein RS, Parfitt AM, Roberson PK, Manolagas SC and Bellido T: Prevention of osteocyte and osteoblast apoptosis by bisphosphonates and calcitonin. J Clin Invest 104: 1363-1374, 1999.

7. Findlay DM, Raggatt LJ, Bouralexis S, Hay S, Atkins GJ and Evdokiou A: Calcitonin decreases the adherence and survival of HEK-293 cells by a caspase-independent mechanism. J Endocrinol 175: 715-725, 2002.

8. McPherson K, Steel CM and Dixon JM: ABC of breast diseases. Breast cancer epidemiology, risk factors, and genetics. Br Med J 321: 624-628, 2000.

9. International Agency for Research on Cancer. Cancer incidence, Mortality and Prevalence Worldwide. IARC Cancer Base No. 5. IARC Press, Lyon, 2001.

10. Andreasen PA, Kjoller L, Christensen L and Duffy MJ: The urokinase-type plasminogen activator system in cancer metastasis: a review. Int J Cancer 72: 1-22, 1997.

11. Rabbani SA and Xing RH: Role of urokinase (uPA) and its receptor (UPAR) in invasion and metastasis of hormone-dependent malignancies. Int J Oncol 12: 911-920, 1998.
12. Reuning U, Magdolen V, Wilhelm O, Fischer K, Lutz V, Graeff H and Schmitt M: Multifunctional potential of the plasminogen activation system in tumor invasion and metastasis. Int $\mathrm{J}$ Oncol 13: 893-906, 1998.

13. Han B, Nakamura M, Mori I, Nakamura Y and Kakudo K: Urokinase-type plasminogen activator system and breast cancer. Oncol Rep 14: 105-112, 2005.

14. Jänicke F, Prechtl A, Thomssen C, et al: Randomized adjuvant therapy trial in high-risk lymph node-negative breast cancer patients identified by urokinase-type plasminogen activator and plasminogen inhibitor type I. J Natl Cancer Inst 93: 913-920, 2001.

15. Look MP, van Putten WL, Duffy MJ, et al: Pooled analysis of prognostic impact of urokinase-type plasminogen activator and its inhibitor PAI-1 in 8377 breast cancer patients. J Natl Cancer Inst 94: 116-128, 2002.

16. Hayes DF, Bast RC, Desch CE, et al: Tumor marker utility grading system: a framework to evaluate clinical utility of tumor markers. J Natl Cancer Inst 88: 1456-1466, 1996.

17. Ossowski L, Russo-Payne $\mathrm{H}$ and Wilson EL: Inhibition of urokinase-type plasminogen activator by antibodies: the effect on dissemination of a human tumor in the nude mouse. Cancer Res 51: 274-281, 1991.

18. Guo Y, Higazi AA, Arakelian A, et al: A peptide derived from the non-receptor binding region of urokinase plasminogen activator (UPA) inhibits tumor progression and angiogenesis and induces tumor cell death in vivo. FASEB J 14: 1400-1410, 2000.

19. Rabbani SA and Gladu J: Urokinase receptor antibody can reduce tumor volume and detect the presence of occult tumor metastases in vivo. Cancer Res 62: 2390-2397, 2002.

20. Aguirre Ghiso JA, Alonso DF, Farias EF, Gomez DE and De Kier Joffe EB: Deregulation of the signaling pathways controlling urokinase production. Its relationship with the invasive phenotype. Eur J Biochem 263: 295-304, 1999.

21. Segawa N, Nakamura M, Nakamura Y, Mori I, Katsuoka Y and Kakudo K: Phosphorylation of mitogen-activated protein kinase is inhibited by calcitonin in DU145 prostate cancer cells. Cancer Res 61: 6060-6063, 2001

22. Ma Z, Webb DJ, Jo M and Gonias SL: Endogenously produced urokinase-type plasminogen activator is a major determinant of the basal level of activated ERK/MAP kinase and prevents apoptosis in MDA-MB-231 breast cancer cells. J Cell Sci 14: 3387-3396, 2001.

23. Seddighzadeh M, Zhou JN, Kronenwett U, et al: ERK signalling in metastatic human MDA-MB-231 breast carcinoma cells is adapted to obtain high urokinase expression and rapid cell proliferation. Clin Exp Metastasis 17: 649-654, 1999.

24. Nakamura M, Yang Q, Ozaki T, Nakamura Y, Yamasaki H, Mori I and Kakudo K: Induction of uPA but not NF-IL3A by calcitonin is dependent on Erk1/2 phosphorylation in porcine renal cell line LLC-PK1. Biochem Biophys Res Commun 290: 1483-1488, 2002.

25. Nakamura Y, Yasuoka H, Tsujimoto M, et al: Lymph vessel density correlates with nodal status, VEGF-C expression, and prognosis in breast cancer. Breast Cancer Res Treat 91: 125-132, 2005 .

26. Guo Y, Pakneshan P, Gladu J, Slack A, Szyf M and Rabbani SA: Regulation of DNA methylation in human breast cancer. Effect on the urokinase-type plasminogen activator gene production and tumor invasion. J Biol Chem 277: 41571-41579, 2002.

27. Holst-Hansen C, Johannessen B, Hoyer-Hansen G, Romer J, Ellis $\mathrm{V}$ and Brunner N: Urokinase-type plasminogen activation in three human breast cancer cell lines correlates with their in vitro invasiveness. Clin Exp Metastasis 14: 297-307, 1996.

28. Yang X, Wei LL, Tang C, Slack R, Mueller S and Lippman ME: Overexpression of KAI1 suppresses in vitro invasiveness and in vivo metastasis in breast cancer cells. Cancer Res 61: 5284-5288, 2001.

29. Rong H, Ji H, Tsai JA, Pernow Y and Bucht E: Calcitoninsuppressed expression of parathyroid hormone-related protein in breast cancer cells. Biochem Biophys Res Commun 265: 260-264, 1999.

30. Lacroix M, Siwek B and Body JJ: Breast cancer cell response to calcitonin: modulation by growth-regulating agents. Eur J Pharmacol 344: 279-286, 1998.

31. Lacroix M and Body JJ: Regulation of c-fos and c-jun expression by calcitonin in human breast cancer cells. Calcif Tissue Int 60: 513-519, 1997. 
32. Gillespie MT, Thomas RJ, Pu ZY, Zhou H, Martin TJ and Findlay DM: Calcitonin receptors, bone sialoprotein and osteopontin are expressed in primary breast cancers. Int $\mathrm{J}$ Cancer 73 : 812-815, 1997.

33. Wang X, Nakamura M, Mori I, et al: Calcitonin receptor gene and breast cancer: quantitative analysis with laser capture microdissection. Breast Cancer Res Treat 83: 109-117, 2004.

34. Bartsch JE, Staren ED and Appert HE: Matrix metalloproteinase expression in breast cancer. J Surg Res 110: 383-392, 2003.
35. Sabbisetti VS, Chirugupati S, Thomas S, et al: Calcitonin increases invasiveness of prostate cancer cells: Role for cyclic AMPdependent protein kinase $\mathrm{A}$ in calcitonin action. Int J Cancer 117: 551-560, 2005.

36. Chigurupati S, Kulkarni T, Thomas S and Shah G: Calcitonin stimulates multiple stages of angiogenesis by directly acting on endothelial cells. Cancer Res 65: 8519-8529, 2005.

37. Chakraborty M, Chatterjee D, Kellokumpu S, Rasmussen H and Baron R: Cell cycle-dependent coupling of the calcitonin receptor to different G proteins. Science 251: 1078-1082, 1991. 